\title{
EVENTOS ADVERSOS RELACIONADOS À SONDA ENTERAL: REVISÃO INTEGRATIVA
}

\author{
ADVERSE EVENTS INVOLVING ENTERAL TUBES: \\ AN INTEGRATIVE REVIEW
}

\section{EVENTOS ADVERSOS RELACIONADOS A LAS SONDAS ENTERALES: REVISIÓN INTEGRATIVA}

\author{
Franciele Anziliero ${ }^{1}$ \\ Bárbara Amaral da Silva² \\ Bárbara Elis Dal Soler ${ }^{3}$ \\ Ana Paula Almeida Corrêa ${ }^{4}$ \\ Mariur Gomes Beghetto
}

Como citar este artigo: Anziliero F, Silva BA, Dal Soler BE, Corrêa APA, Beghetto MG. Eventos adversos relacionados à sonda enteral: revisão integrativa. Rev baiana enferm. 2019;33:e33850.

\begin{abstract}
Objetivo: conhecer os eventos adversos relacionados à inserção, manutenção e remoção de sonda enteral descritos na literatura. Método: trata-se de uma revisão integrativa de literatura. A estratégia PICO foi utilizada para formulação da questão norteadora. Foram selecionados artigos das bases PubMed, Embase e Scopus, publicados entre junho de 2009 e junho de 2019, nas línguas portuguesa, espanhola e inglesa. Resultados: foram incluídos 45 estudos, categorizados em eventos adversos relacionados à inserção da sonda enteral $(n=22)$ que promoveram danos como epistaxe por lesão até a inserção de sonda no átrio direito; eventos relativos à manutenção da sonda e/ou administração de dieta $(n=14)$, como a infusão de dieta em sítio pulmonar; e aqueles ocorridos na remoção $(n=9)$, como emaranhado na ponta distal. Conclusão: diferentes eventos adversos descritos na literatura podem ocorrer na inserção, manutenção, administração de dieta e remoção da sonda enteral.
\end{abstract}

Descritores: Intubação Gastrointestinal. Cuidados de Enfermagem. Nutrição Enteral. Segurança do Paciente. Potencial Evento Adverso na Assistência à Saúde.

Objective: surveying scientific literature with regards to adverse events related to the insertion, maintenance, and removal of enteral tubes. Method: this is an integrative literature review. The PICO strategy was used to elaborate the guiding question. This research reviewed articles published from June 2009 to July 2019 in Portuguese, Spanish and English, in the databases PubMed, Embase and Scopus. Results: 45 studies were included and categorized as adverse events involving enteral tubes related to the insertion of the tube $(n=22)$, which caused damage such as epistaxis caused by lesion and insertion of the tube in the right-side atrium; events related to the maintenance of the tube and/or administration of the diet $(n=14)$, such as infusing the diet into the lungs; and those related to tube removal $(n=9)$, such as entanglements in the distal end. Conclusion: different adverse events described in literature can take place during the insertion, maintenance, diet administration, and removal of the enteral tube.

Descriptor: Intubation, Gastrointestinal. Nursing Care. Enteral Nutrition. Patient Safety. Near Miss, Healthcare.

\footnotetext{
Enfermeira. Mestre em Enfermagem. Universidade Federal do Rio Grande do Sul. Porto Alegre, Rio Grande do Sul, Brasil. francieleanziliero@gmail.com. https://orcid.org/0000-0002-5650-9709

Enfermeira. Pesquisadora independente. Porto Alegre, Rio Grande do Sul, Brasil. https://orcid.org/0000-000 I-9498-276X

Enfermeira. Pesquisadora independente. Porto Alegre, Rio Grande do Sul, Brasil. https://orcid.org/0000-0003-0867-4897

Enfermeira. Doutora em Enfermagem. Enfermeira Assistencial no Hospital de Clínicas de Porto Alegre. Porto Alegre, Rio Grande do Sul, Brasil. https://orcid.org/00000001-8890-1767

Enfermeira. Doutora em Epidemiologia. Professora da Universidade Federal do Rio Grande do Sul. Porto Alegre, Rio Grande do Sul, Brasil. https://orcid.org/00000003-0867-4897
} 
Objetivo: conocer los eventos adversos relacionados a la inserción, manutención y remoción de una sonda enteral descritos en la literatura. Método: esa es una revisión integrativa de la literatura. Se utilizó a la estrategia PICO para formular la pregunta rectora. Se seleccionó articulos de las bases PubMed, Embase y Scopus publicados de junio de 2009 hasta julio de 2019 en portugués, español e inglés. Resultados: se incluyó 45 estudios y se les categorizó como eventos adversos relacionados a la inserción de la sonda enteral $(n=22)$ y que causaron daños como epistaxis por lesión e inserción de la sonda en la aurícula derecha; eventos relacionados a la manutención de la sonda y/o la administración de dieta $(n=14)$, como la infusión de la dieta en sitio pulmonar; y eventos relacionados a la remoción de la sonda $(n=9)$, como el enmarañamiento del extremo distal de la sonda. Conclusión: diversos eventos adversos descritos en la literatura pueden ocurrir en la inserción, manutención, administración de dieta y remoción de la sonda enteral.

Descriptores: Intubación Gastrointestinal. Atención de Enfermería. Nutrición Enteral. Seguridad del Paciente. Near Miss Salud.

\section{Introdução}

As Sondas Enterais (SE) de inserção nasal são utilizadas para pacientes sem condições de receber alimentação por via oral, mas que mantém o Trato Gastrointestinal (TGI) íntegro ${ }^{(1)}$. Na prática clínica, as sondas tipo Dobbhoff® com fio guia são as mais utilizadas, podendo ter a ponta distal posicionada pré ou pós-pilórica conforme características do paciente $^{(2)}$.

Embora não existam censos que mensurem a utilização das SE, elas são frequentemente empregadas em pacientes hospitalizados e mesmo após a alta, em Instituições de Longa Permanência ou no domicílio ${ }^{(1-2)}$. Nesses ambientes, o enfermeiro é o profissional responsável, nas diferentes etapas de cuidado a usuários desse dispositivo, desde a inserção e manutenção até a remoção da sonda ${ }^{(3-4)}$.

Os processos envolvidos na assistência aos pacientes que necessitam de alimentação por sonda guardam riscos de incidentes ou Eventos Adversos (EA) ${ }^{(1)}$. Por definição do Ministério da Saúde brasileiro, incidente é descrito como "Evento ou circunstância que poderia ter resultado, ou resultou, em dano desnecessário ao paciente"(5:7), enquanto EA é conceituado como qualquer "Incidente que resulta em dano ao paciente" ${ }^{(5: 7)}$. Nesse sentido, um dos EA mais conhecidos e mais temidos é a broncopneumonia decorrente da administração da terapêutica no trato respiratório, secundária à localização incorreta da SE ou ao refluxo de conteúdo gástrico pela posição esofágica da ponta distal da sonda ${ }^{(6-7)}$.
Em estudo de revisão ${ }^{(6)}$ que agregou 9.931 inserções de SE, os autores encontraram proporção de 1,9\% $(n=187)$, em que a ponta distal encontrava-se nos brônquios ou no pulmão. Desses 18,7\% (n=35) apresentavam pneumotórax associado ao mau posicionamento e pelo menos cinco deles resultaram em morte do paciente. Proporção menor de posicionamento inadequado da SE foi relatado em estudo brasileiro ${ }^{(7)}$. Das 150 inserções em pacientes clínicos acompanhados em uma emergência, 1,3\% teve o exame de imagem indicando a posição da ponta distal como de risco para administração de terapêutica. Um óbito foi associado à broncoaspiração de $\operatorname{dieta}^{(7)}$.

Outros eventos relacionados à SE e de grande potencial para danos são descritos na literatura, habitualmente por meio de relatos de caso. Dentre eles, cabe destacar a Síndrome da Sonda Enteral, na qual ocorrem lesões da mucosa laríngea e paresia das pregas vocais ${ }^{(8-9)}$, laceração esofágica em consequência de remoção da sonda emaranhada em si mesma ${ }^{(10)}$, perfuração gástrica $^{(11)}$, inserção da sonda no cérebro ${ }^{(12-14)}$, pneumotórax hipertensivo ${ }^{(15)}$, queimadura de segundo grau em virtude da desconexão da sonda e refluxo do suco gástrico ${ }^{(16)}$, entre outros.

Assim, frente a esses incidentes ou EA decorrentes das práticas inerentes às etapas da assistência ao usuário de SE, parece importante a difusão de estudos que sintetizem tais achados. A desinformação das equipes assistenciais, dos pacientes e de seus cuidadores sobre 
a real magnitude e possíveis desfechos clínicos relacionados à inserção, manutenção e remoção da $\mathrm{SE}^{(1)}$ pode acarretar menor atenção empregada na execução das rotinas relativas à nutrição enteral. Quanto mais os atores envolvidos conhecerem sobre o tema ${ }^{(17)}$, mais capazes serão de reconhecer os riscos potenciais referentes à SE, podendo adotar ações preventivas ${ }^{(1)}$ que promovam assistência em consonância com as diretrizes de segurança do paciente ${ }^{(5)}$.

Este estudo objetiva conhecer os eventos adversos relacionados à inserção, manutenção e remoção de sonda enteral descritos na literatura.

\section{Método}

Trata-se de uma revisão integrativa da literatura, que seguiu as fases de elaboração da pergunta norteadora, busca na literatura, coleta dos dados, análise crítica dos estudos selecionados, incluindo avaliação do nível de evidência, discussão dos resultados e apresentação da revisão integrativa ${ }^{(18)}$. Além disso, foram observados os itens da recomendação PRISMA (Transparent Reporting of Systematic Reviews and Meta-analyses) ${ }^{(19)}$.

$\mathrm{Na}$ primeira fase, para elaboração da pergunta norteadora, utilizou-se a estratégia PICO $^{(20)}$, sendo: P (paciente/população) - pacientes adultos usuários de SE inserção nasal; I (intervenção) - qualquer atividade assistencial relacionada à inserção, manutenção ou remoção de sondas enterais; C (controle) - não se aplica; O (resultado) - qualquer evento adverso relacionado à inserção, manutenção ou remoção de sondas enterais. Dessa forma, a pergunta norteadora foi assim enunciada: Quais são os incidentes e eventos adversos descritos na literatura, relacionados à inserção, manutenção e remoção da SE em pacientes adultos?

Para definição de Incidentes e Evento Adverso (EA) foi utilizado o documento de referência do Ministério da Saúde brasileiro, sendo o primeiro descrito como "Evento ou circunstância que poderia ter resultado, ou resultou, em dano desnecessário ao paciente"(5:7), enquanto EA é qualquer "Incidente que resulta em algum dano ao paciente" ${ }^{(5: 7)}$.
$\mathrm{Na}$ fase de busca, foram selecionados estudos clínicos, incluindo relatos de caso, envolvendo pacientes maiores de 18 anos, publicados nas bases U.S. National Library of Medicine (PubMed), Embase e Scopus Info Site (Scopus), entre junho de 2009 e junho de 2019, nas línguas portuguesa, espanhola e inglesa. O período de busca, nos últimos dez anos, foi determinado pela necessidade de reportar resultados recentes e que refletissem as práticas mais atuais com relação à temática.

$\mathrm{Na}$ estratégia de busca, foram adotados os seguintes descritores: Intubation, Nasogastric; Gastrointestinal Intubation; Intubation, Gastrointestinal; Enteral Feeding Tube, combinados entre si pelo operador boleano $O R$. Embora não esteja descrito no Medical Subject Headings (MeSH), o termo "Enteral Feeding Tube" foi incluído na pesquisa, por ser amplamente utilizado na prática clínica e em publicações da área.

Adicionalmente aos descritores relacionados à SE, utilizou-se o operador boleano $A N D$ para Adverse Effects, Pneumonia, Pneumothorax, Brain Injuries, Lung Injury e Nursing. A utilização desses descritores foi motivada por busca prévia, na qual apenas os termos referentes a SE e Adverse Effects haviam sido empregados. No entanto, observou-se um número muito restrito de resultados. Assim, ao adicionar os demais termos, a pesquisa abrangeu outros incidentes e eventos adversos possíveis, conforme descrito nos resultados.

No presente estudo, não foram incluídas pesquisas referentes à gastrostomia ou jejunostomia. Essa opção deu-se, principalmente, pelas diferenças em suas características de inserção e cuidados. Igualmente, os estudos que estavam presentes em mais de uma base de dados foram contabilizados na fase inicial de busca, sendo utilizada a primeira plataforma pesquisada (PubMed) como referência para exclusão das repetições.

A busca nas bases de dados foi realizada por duas pesquisadoras independentes, que seguiram os mesmos critérios de seleção (descritores), filtros (humanos, idade $>18$ anos, idioma e período de publicação) e a mesma ordem de 
leitura: títulos, resumos e artigo completo. Ao final de cada etapa, as revisoras reuniam-se para consenso. As discordâncias foram resolvidas com a presença de uma terceira revisora. Os artigos selecionados foram incluídos em um banco de dados.

Para análise dos dados, foram construídos quadros sinópticos contemplando as seguintes informações: título, autores, ano de publicação, país de origem do artigo, perfil de pacientes, delineamento adotado, incidente ou evento adverso reportado, possíveis danos causados ao paciente, demanda de cuidados adicionais referentes ao EA, além de informações sobre a evolução clínica do paciente. Os achados foram agrupados em categorias, de acordo com a etapa do processo de utilização da SE em que o incidente ou EA ocorreu: inserção da SE; manutenção da sonda e administração da dieta e remoção da SE. Cabe destacar que os artigos nos quais a sonda foi inserida em sítio pulmonar e que houve dano secundário à administração de dieta foram alocados na categoria "manutenção da sonda e administração da dieta".

Figura 1 - Fluxograma de seleção dos artigos

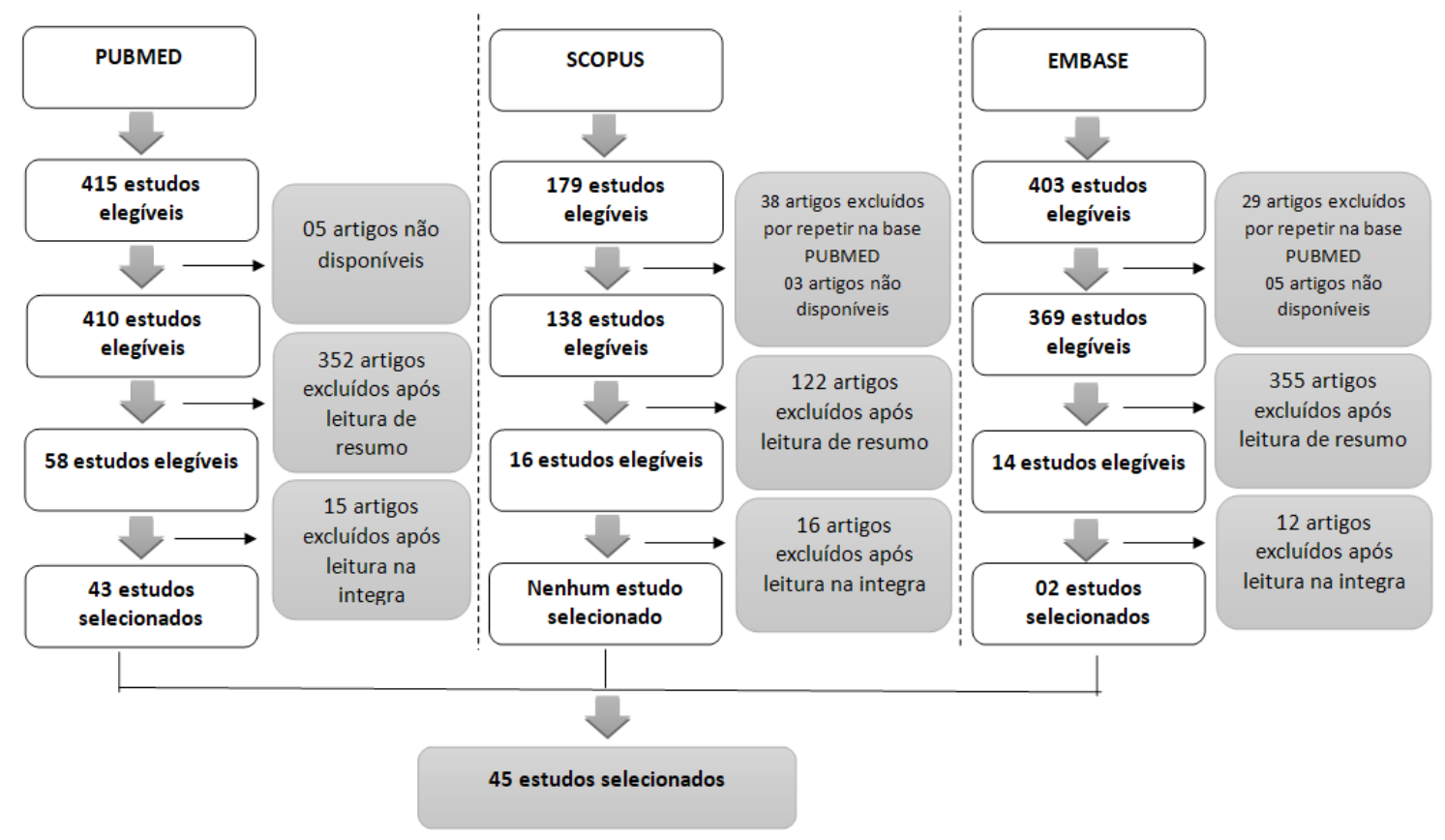

A presente revisão foi conduzida de acordo com a legislação brasileira sobre direitos autorais ${ }^{(21-22)}$ e está vinculada a um projeto maior cujos aspectos éticos e metodológicos foram avaliados por Comitê de Ética em Pesquisa da instituição sede do estudo.

\section{Resultados}

A Figura 1 apresenta os dados referentes ao percurso para a seleção dos artigos. Do total de artigos, 88 foram lidos na íntegra, selecionando-se 45 para integrarem a presente revisão. Os relatos de caso constituíram a maior parte da amostra $(n=44)$. As exclusões na primeira fase da revisão deram-se principalmente por repetição em relação à primeira base de dados consultada (PubMed). Maior número de exclusões deu-se na leitura dos resumos, por abordarem: gastrostomia, jejunostomia e ileostomia; métodos de inserção e verificação do posicionamento de SE; testes de administração de medicamentos ou vitaminas via SE; estudos em neonatos (mesmo utilizando o filtro para idade); complicações gastrointestinais.

Fonte: Elaboração própria. 
Do total de artigos selecionados, 22 descreveram eventos adversos relacionados ao procedimento de inserção da sonda enteral (Quadro 1). Eles foram publicados, maioritariamente, em $2011(n=4), 2012(n=4)$ e $2015(n=4)$. Espanha $(n=5)$ e Estados Unidos da América $(n=4)$ foram os países que mais publicaram. As complicações na inserção da sonda enteral foram de diferentes gravidades, desde incidentes sem nenhum dano agregado à EA, como a inserção no cérebro, causando extravasamento de liquor. Cabe destacar que, em 77\% dos casos, o paciente necessitou de exame ou procedimento adicional relacionado ao ED causado pela inserção da sonda. Cinco estudos relataram óbito como desfecho clínico. Quatros estudos não relataram necessidade de cuidados adicionais e nove não apresentaram desfecho clínico do paciente.

Quadro 1 - Caracterização dos estudos nos quais o evento adverso ocorreu na etapa de inserção da sonda enteral

(continua)

\begin{tabular}{|c|c|c|}
\hline País /Ano & Evento Adverso / Perfil do paciente & $\begin{array}{l}\text { Demanda de cuidados adicionais } \\
\text { / evolução clínica do paciente }\end{array}$ \\
\hline $\begin{array}{l}\text { Reino Unido } \\
2012^{(11)}\end{array}$ & $\begin{array}{l}\text { Perfuração gástrica após inserção. } \\
\text { Homem, } 32 \text { anos, admitido por aneurisma de } \\
\text { artéria hepática esquerda roto. Diagnóstico } \\
\text { diferencial de Displasia Fibromuscular. }\end{array}$ & $\begin{array}{l}\text { Tomografia abdominal, Raios-X e } \\
\text { Laparotomia de urgência. } \\
\text { Estudo não relata evolução clínica. }\end{array}$ \\
\hline $\begin{array}{l}\text { Grécia } \\
2012^{(12)}\end{array}$ & $\begin{array}{l}\text { Inserção no cérebro. } \\
\text { Homem, } 52 \text { anos, admitido por traumatismo } \\
\text { craniano após acidente automobilístico. }\end{array}$ & $\begin{array}{l}\text { Antibiótico profilático e tomografia. } \\
\text { Estudo não relatou evolução clínica. }\end{array}$ \\
\hline $\begin{array}{l}\text { Índia } \\
2010^{(13)}\end{array}$ & $\begin{array}{l}\text { Inserção no cérebro. } \\
\text { Homem, } 45 \text { anos admitido por traumatismo } \\
\text { craniofacial severo em acidente automobilístico. }\end{array}$ & $\begin{array}{l}\text { Cuidados críticos e Ventilação } \\
\text { mecânica. } \\
\text { Óbito. }\end{array}$ \\
\hline $\begin{array}{l}\text { Itália } \\
2011^{(14)}\end{array}$ & $\begin{array}{l}\text { Inserção no cérebro, através do seio frontal. } \\
\text { Homem, } 80 \text { anos, admitido por hemorragia } \\
\text { cerebral. }\end{array}$ & $\begin{array}{l}\text { Tomografia. } \\
\text { Estudo não relata evolução clínica. }\end{array}$ \\
\hline $\begin{array}{l}\text { India } \\
2010^{(23)}\end{array}$ & $\begin{array}{l}\text { Inserção na primeira porção do brônquio } \\
\text { esquerdo. } \\
\text { Homem, } 60 \text { anos, admitido na Unidade de } \\
\text { Tratamento Intensivo por disfagia. }\end{array}$ & $\begin{array}{l}\text { Ventilação Mecânica. } \\
\text { Óbito. }\end{array}$ \\
\hline $\begin{array}{l}\text { Nepal } \\
2010^{(24)}\end{array}$ & $\begin{array}{l}\text { Inserção no hemisfério esquerdo do cérebro. } \\
\text { Homem, } 55 \text { anos, admitido por traumatismo } \\
\text { craniano causado por colheitadeira de milho. }\end{array}$ & $\begin{array}{l}\text { Ventilação Mecânica. } \\
\text { Óbito após seis dias de internação. }\end{array}$ \\
\hline $\begin{array}{l}\text { China } \\
2011^{(25)}\end{array}$ & $\begin{array}{l}\text { Perfuração de intestino delgado pela sonda. } \\
\text { Homem, } 78 \text { anos, admitido por dor abdominal, } \\
\text { após recolocação de sonda. Histórico de } \\
\text { gastrectomia por câncer. }\end{array}$ & $\begin{array}{l}\text { Tomografia e laparotomia de } \\
\text { urgência. Sonda Enteral substituída } \\
\text { por jejunostomia. } \\
\text { Óbito } 19 \text { dias após a cirurgia. }\end{array}$ \\
\hline $\begin{array}{l}\text { Espanha } \\
2011^{(26)}\end{array}$ & $\begin{array}{l}\text { Perfuração de esôfago. Ponta distal da sonda } \\
\text { em cavidade pleural direita. } \\
\text { Paciente de sexo não relatado, } 88 \text { anos, } \\
\text { admitido por impactação de bolo alimentar no } \\
\text { esôfago. }\end{array}$ & $\begin{array}{l}\text { Tomografia de tórax, toracotomia } \\
\text { de urgência, antibioticoterapia. } \\
\text { Alta hospitalar } 20 \text { dias após a } \\
\text { admissão. }\end{array}$ \\
\hline $\begin{array}{l}\text { Reino Unido } \\
2011^{(27)}\end{array}$ & $\begin{array}{l}\text { Inserção no brônquio principal direito } \\
\text { causando pneumotórax. } \\
\text { Mulher, } 44 \text { anos, admitida por Acidente } \\
\text { Vascular Cerebral Isquêmico. }\end{array}$ & $\begin{array}{l}\text { Dreno de tórax. } \\
\text { Estudo não relata evolução clínica. }\end{array}$ \\
\hline
\end{tabular}


Quadro 1 - Caracterização dos estudos nos quais o evento adverso ocorreu na etapa de inserção da sonda enteral

(continua)

\begin{tabular}{|c|c|c|}
\hline País /Ano & Evento Adverso / Perfil do paciente & $\begin{array}{l}\text { Demanda de cuidados adicionais } \\
\text { / evolução clínica do paciente }\end{array}$ \\
\hline $\begin{array}{l}\text { Espanha } \\
2012^{(28)}\end{array}$ & $\begin{array}{l}\text { Perfuração do espaço retrofaríngeo, acessando } \\
\text { a rede venosa através do tronco venoso facial } \\
\text { (jugular interna e veia cava superior), ponta } \\
\text { distal alojada no átrio direito e presa aos fios } \\
\text { de marca-passo. } \\
\text { Homem, } 76 \text { anos, admitido por hemorragia } \\
\text { subaracnoide. Histórico de carcinoma de } \\
\text { pregas vocais. }\end{array}$ & $\begin{array}{l}\text { Raio-X de tórax, tomografia e } \\
\text { angiografia para retirada da sonda. } \\
\text { Estudo não relata evolução clínica. }\end{array}$ \\
\hline $\begin{array}{l}\text { Estados } \\
\text { Unidos da } \\
\text { América } \\
2012^{(29)}\end{array}$ & $\begin{array}{l}\text { Inserção no tronco cerebral e medula com } \\
\text { extravasamento de líquido cefalorraquidiano. } \\
\text { Homem, } 57 \text { anos, admitido pós-operatório de } \\
\text { ressecção de Cormoma Clívus. }\end{array}$ & $\begin{array}{l}\text { Tomografia e cirurgia para remoção } \\
\text { da sonda. } \\
\text { Óbito. }\end{array}$ \\
\hline $\begin{array}{l}\text { Índia } \\
2013^{(30)}\end{array}$ & $\begin{array}{l}\text { Inserção na traqueia causando laringosespasmo. } \\
\text { Homem, } 45 \text { anos, admitido para colecistectomia. }\end{array}$ & $\begin{array}{l}\text { Estudo não relata cuidados } \\
\text { adicionais. } \\
\text { Alta hospitalar. }\end{array}$ \\
\hline $\begin{array}{l}\text { França } \\
2013^{(31)}\end{array}$ & $\begin{array}{l}\text { Inserção na traqueia, durante cirurgia de } \\
\text { redução de estômago. } \\
\text { Mulher, } 44 \text { anos, admitida para bypass gástrico. }\end{array}$ & $\begin{array}{l}\text { Estudo não relata cuidados } \\
\text { adicionais. } \\
\text { Estudo não relata evolução clínica. }\end{array}$ \\
\hline $\begin{array}{l}\text { Estados } \\
\text { Unidos da } \\
\text { América } \\
2013^{(32)}\end{array}$ & $\begin{array}{l}\text { Inserção causou extravasamento de } \\
\text { pseudoaneurisma no ramo faríngeo, causando } \\
\text { epistaxe grave. } \\
\text { Mulher, } 53 \text { anos, admitida por infecção } \\
\text { respiratória, dor abdominal e vômitos. }\end{array}$ & $\begin{array}{l}\text { Embolização do pseudoaneurisma e } \\
\text { cuidados críticos. Antibioticoterapia. } \\
\text { Alta hospitalar. }\end{array}$ \\
\hline $\begin{array}{l}\text { Espanha } \\
2015^{33)}\end{array}$ & $\begin{array}{l}\text { Inserção no pulmão direto, ocasionando } \\
\text { pneumotórax. } \\
\text { Mulher, } 82 \text { anos, admitida por disfagia. }\end{array}$ & $\begin{array}{l}\text { Dreno de tórax. } \\
\text { Estudo não relata evolução clínica. }\end{array}$ \\
\hline $\begin{array}{l}\text { Estados } \\
\text { Unidos da } \\
\text { América } \\
2015^{(34)}\end{array}$ & $\begin{array}{l}\text { Inserção durante cirurgia de correção de fratura } \\
\text { de face, ponta distal da sonda em lobo inferior } \\
\text { esquerdo do pulmão. } \\
\text { Homem, } 64 \text { anos, admitido após fratura de face. }\end{array}$ & $\begin{array}{l}\text { Estudo não relata cuidados } \\
\text { adicionais. } \\
\text { Alta hospitalar. }\end{array}$ \\
\hline $\begin{array}{l}\text { Portugal } \\
2015^{(35)}\end{array}$ & $\begin{array}{l}\text { Inserção no pulmão direito, causando derrame } \\
\text { pleural e hidropneumotórax. } \\
\text { Mulher, } 62 \text { anos, admitida na ala psiquiátrica } \\
\text { por desnutrição severa. }\end{array}$ & $\begin{array}{l}\text { Paciente necessitou de Raio-X de } \\
\text { tórax, tomografia e dreno de tórax. } \\
\text { Ressecção atípica de pulmão. } \\
\text { Estudo relata melhora clínica. }\end{array}$ \\
\hline $\begin{array}{l}\text { Espanha } \\
2015^{(36)}\end{array}$ & $\begin{array}{l}\text { Inserção no pulmão direito causando } \\
\text { hidropneumotórax. } \\
\text { Mulher, } 46 \text { anos, admitida na Unidade } \\
\text { de Tratamento Intensivo por hemorragia } \\
\text { subaracanoide. }\end{array}$ & $\begin{array}{l}\text { Estudo não relata cuidados } \\
\text { adicionais. } \\
\text { Estudo não relata evolução clínica. }\end{array}$ \\
\hline $\begin{array}{l}\text { Arábia } \\
\text { Saudita } \\
2015^{(37)}\end{array}$ & $\begin{array}{l}\text { Inserção no brônquio principal direito com } \\
\text { ponta distal no espaço pleural, causando } \\
\text { pneumotórax. } \\
\text { Homem, } 60 \text { anos, admitido por diarreia. }\end{array}$ & $\begin{array}{l}\text { Dreno de tórax. } \\
\text { Estudo relata evolução clínica } \\
\text { favorável. }\end{array}$ \\
\hline $\begin{array}{l}\text { Espanha } \\
2016^{(38)}\end{array}$ & $\begin{array}{l}\text { Inserção no pulmão direito durante } \\
\text { procedimento cirúrgico. } \\
\text { Homem, } 64 \text { anos, admitido por abscesso } \\
\text { cervical. }\end{array}$ & $\begin{array}{l}\text { Múltiplas tentativas para reinserção } \\
\text { da sonda. } \\
\text { Estudo não relata evolução clínica. }\end{array}$ \\
\hline
\end{tabular}


Quadro 1 - Caracterização dos estudos nos quais o evento adverso ocorreu na etapa de inserção da sonda enteral

(conclusão)

\begin{tabular}{|l|l|l|}
\hline \multicolumn{1}{|c|}{ País /Ano } & \multicolumn{1}{|c|}{ Evento Adverso / Perfil do paciente } & $\begin{array}{l}\text { Demanda de cuidados adicionais } \\
\text { / evolução clínica do paciente }\end{array}$ \\
\hline $\begin{array}{l}\text { Estados } \\
\text { Unidos da } \\
\text { América } \\
2018^{(39)}\end{array}$ & $\begin{array}{l}\text { Múltiplas tentativas de inserção, causando } \\
\text { pneumotórax bilateral. } \\
\text { Homem, 74 anos, admitido por politrauma por } \\
\text { atropelamento. }\end{array}$ & $\begin{array}{l}\text { Raio-X diário e dreno de tórax } \\
\text { bilateral. } \\
\text { Alta hospitalar. }\end{array}$ \\
\hline $\begin{array}{l}\text { Singapura } \\
2019^{(40)}\end{array}$ & $\begin{array}{l}\text { Inserção no brônquio principal direito } \\
\text { causando pneumotórax. } \\
\text { Homem, 72 anos, admitido por Acidente } \\
\text { Vascular Cerebral Isquêmico. }\end{array}$ & $\begin{array}{l}\text { Dreno de tórax, tomografia } \\
\text { toracoscopia e ressecção do lobo } \\
\text { inferior direito. } \\
\text { Alta hospitalar. }\end{array}$ \\
\hline
\end{tabular}

Fonte: Elaboração própria.

Em 14 publicações, oriundas de diversos países e predominantemente divulgadas em $2012(n=4)$ e $2018(n=3)$, foram identificados EA que se referem à manutenção da sonda e/ou administração de dieta (Quadro 2). O EA mais frequente foi a administração da dieta na via respiratória $(n=6)$, seguida da Síndrome da sonda enteral $(n=3)$ e da formação de bezoar $(n=3)$, entre outros eventos. É importante destacar que apenas um estudo não relatou exames ou procedimentos adicionais. Os demais descreveram a necessidade de dreno de tórax, antibioticoterapia, traqueostomia, broncoscopia, endoscopia, ventilação mecânica e utilização de agente enzimático, nos casos de formação de bezoar. Um paciente necessitou Oxigenação Extracorpórea (ECMO). Apesar de mais da metade dos estudos descreverem como evolução clínica a melhora, alta hospitalar ou transferência, dois casos tiveram como desfecho o óbito do paciente. Dois estudos não relatam desfecho.

Quadro 2 - Caracterização dos estudos nos quais o evento adverso ocorreu na etapa de manutenção da sonda e/ou administração de dieta

\begin{tabular}{|l|l|l|}
\hline \multicolumn{1}{|c|}{$\begin{array}{c}\text { País / } \\
\text { Ano }\end{array}$} & \multicolumn{1}{|c|}{ Evento Adverso / Perfil do paciente } \\
\hline $\begin{array}{l}\text { Brasil } \\
2018^{(7)}\end{array}$ & $\begin{array}{l}\text { Ponta distal voltada para o esôfago. Aspiração } \\
\text { de dieta. A sonda foi retirada e reinserida, } \\
\text { novamente a dieta foi administrada em posição } \\
\text { de risco. } \\
\text { Estudo não relatou dados do paciente. }\end{array}$ & $\begin{array}{l}\text { Não foram descritas demandas } \\
\text { evolução clínica do paciente } \\
\text { Óbito. }\end{array}$ \\
\hline $\begin{array}{l}\text { Japão } \\
2016^{(8)}\end{array}$ & $\begin{array}{l}\text { Síndrome da sonda enteral. Lesão laríngea } \\
\text { provocada pela sonda, causando paresia das } \\
\text { pregas vocais e edema laríngeo. } \\
\text { Homem, 76 anos, admitido para tratamento de } \\
\text { câncer no cólon. }\end{array}$ & $\begin{array}{l}\text { Broncoscopia, ventilação mecânica e } \\
\text { traqueostomia. } \\
\text { Alta hospitalar. }\end{array}$ \\
\hline $\begin{array}{l}\text { Espanha } \\
2010^{(9)}\end{array}$ & $\begin{array}{l}\text { Síndrome da sonda Enteral. Lesão laríngea } \\
\text { provocada pela sonda, causando paresia das } \\
\text { pregas vocais e edema laríngeo. } \\
\text { Mulher, 70 anos, admitida por Acidente Vascular } \\
\text { Cerebral Isquêmico. }\end{array}$ & $\begin{array}{l}\text { Traqueostomia. } \\
\text { Estudo relata melhora clínica. }\end{array}$ \\
\hline $\begin{array}{l}\text { Japão } \\
2009^{(41)}\end{array}$ & $\begin{array}{l}\text { Inserção no pulmão esquerdo, ponta distal no } \\
\text { espaço pleural. Pleurite por infusão de dieta. } \\
\text { Mulher, 87 anos, admitida por pneumonia e } \\
\text { inapetência. }\end{array}$ & $\begin{array}{l}\text { Oreno de tórax e antibioticoterapia. } \\
\text { demonstrou associação entre a } \\
\text { pleurite e o óbito. }\end{array}$ \\
\hline
\end{tabular}


Quadro 2 - Caracterização dos estudos nos quais o evento adverso ocorreu na etapa de manutenção da sonda e/ou administração de dieta

(continua)

\begin{tabular}{|c|c|c|}
\hline $\begin{array}{l}\text { País / } \\
\text { Ano }\end{array}$ & Evento Adverso / Perfil do paciente & $\begin{array}{c}\text { Demanda de cuidados adicionais } \\
\text { evolução clínica do paciente }\end{array}$ \\
\hline $\begin{array}{l}\text { China } \\
2011^{(42)}\end{array}$ & $\begin{array}{l}\text { Inserção no pulmão direito e infusão de dieta } \\
\text { em sítio pulmonar. } \\
\text { Homem, } 49 \text { anos, admitido para cirurgia de } \\
\text { tumor de cabeça e pescoço. }\end{array}$ & $\begin{array}{l}\text { Raio-X, Tomografia de tórax, } \\
\text { broncoscopia e antibioticoterapia por } \\
\text { duas semanas. } \\
\text { Alta hospitalar. }\end{array}$ \\
\hline $\begin{array}{l}\text { China } \\
2012^{(43)}\end{array}$ & $\begin{array}{l}\text { Inserção no pulmão direito com infusão de dieta. } \\
\text { Inflamação pulmonar e derrame pleural. } \\
\text { Homem, } 67 \text { anos, admitido por colite ulcerativa. }\end{array}$ & $\begin{array}{l}\text { Cuidados críticos, ventilação } \\
\text { mecânica e fibrobroncoscopia. } \\
\text { submetido à Oxigenação } \\
\text { Extracorpórea (ECMO). } \\
\text { Alta hospitalar. }\end{array}$ \\
\hline $\begin{array}{l}\text { Reino } \\
\text { Unido } \\
2012^{(44)}\end{array}$ & $\begin{array}{l}\text { Inserção no pulmão direito, com infusão de } \\
\text { dieta em sítio pulmonar. } \\
\text { Homem, } 54 \text { anos, admitido por tumor de cabeça } \\
\text { e pescoço. }\end{array}$ & $\begin{array}{l}\text { Raio-X, antibioticoterapia e } \\
\text { oxigenoterapia. } \\
\text { Transferido para unidade de } \\
\text { cuidados paliativos. }\end{array}$ \\
\hline $\begin{array}{l}\text { Irlanda } \\
2012^{(45)}\end{array}$ & $\begin{array}{l}\text { Obstrução esofágica completa por formação de } \\
\text { bezoar e pneumonia aspirativa. } \\
\text { Homem, } 20 \text { anos, admitido na Unidade de } \\
\text { Tratamento Intensivo por meningoencefalite. }\end{array}$ & $\begin{array}{l}\text { Ventilação mecânica e } \\
\text { antibioticoterapia. Endoscopia para } \\
\text { remoção do bezoar. } \\
\text { Transferência para enfermaria. }\end{array}$ \\
\hline $\begin{array}{l}\text { Espanha } \\
2012^{(46)}\end{array}$ & $\begin{array}{l}\text { Inserção no pulmão direito com infusão de dieta } \\
\text { em sítio pulmonar, causando hidropneumotórax. } \\
\text { Homem, } 77 \text { anos, admitido por pneumonia } \\
\text { aspirativa. História de doença de Parkinson. }\end{array}$ & $\begin{array}{l}\text { Dreno de tórax e antibioticoterapia. } \\
\text { Estudo relata evolução clínica } \\
\text { favorável. }\end{array}$ \\
\hline $\begin{array}{l}\text { Irlanda } \\
2012^{(47)}\end{array}$ & $\begin{array}{l}\text { Caso 1: Inserção no brônquio principal direito, } \\
\text { com infusão de dieta em sítio pulmonar, } \\
\text { causando pneumotórax e pneumonia. } \\
\text { Mulher, } 88 \text { anos, admitida por Acidente Vascular } \\
\text { Cerebral Isquêmico. } \\
\text { Caso 2: Inserção no brônquio principal esquerdo, } \\
\text { com infusão de dieta em sítio pulmonar. } \\
\text { Paciente desenvolveu abscesso pulmonar e } \\
\text { derrame pleural. } \\
\text { Homem, } 73 \text { anos, admitido por Acidente } \\
\text { Vascular Cerebral Isquêmico. }\end{array}$ & $\begin{array}{l}\text { Caso 2: Tomografia de Tórax, dreno } \\
\text { de tórax e antibioticoterapia } \\
\text { Estudo não relata evolução clínica. }\end{array}$ \\
\hline $\begin{array}{l}\text { Itália } \\
2013^{(48)}\end{array}$ & $\begin{array}{l}\text { Formação de looping no estômago com a } \\
\text { ponta distal voltada para o esôfago. Paciente } \\
\text { apresentou vômitos imediatamente após o início } \\
\text { da dieta. } \\
\text { Mulher, } 68 \text { anos, admitida por desnutrição e } \\
\text { disfagia. Alzheimer prévio. }\end{array}$ & $\begin{array}{l}\text { Reposicionamento da sonda enteral } \\
\text { por endoscopia. } \\
\text { Alta hospitalar para instituição de } \\
\text { longa permanência. }\end{array}$ \\
\hline $\begin{array}{l}\text { Espanha } \\
2016^{(49)}\end{array}$ & $\begin{array}{l}\text { Caso 1: Obstrução esofágica por formação de } \\
\text { bezoar no terço distal do esôfago. } \\
\text { Homem, } 66 \text { anos, admitido por coma e } \\
\text { hipotensão. } \\
\text { Caso 2: Obstrução esofágica por formação de } \\
\text { bezoar no terço proximal do esôfago. } \\
\text { Homem, } 67 \text { anos, admitido por choque séptico e } \\
\text { falência respiratória. }\end{array}$ & $\begin{array}{l}\text { Caso 1: Gastroscopia e agente } \\
\text { enzimático para remoção do bezoar. } \\
\text { Estudo não relata evolução clínica. } \\
\text { Caso 2: Gastroscopia e agente } \\
\text { enzimático para remoção do bezoar. } \\
\text { Estudo não relata evolução clínica. }\end{array}$ \\
\hline
\end{tabular}


Quadro 2 - Caracterização dos estudos nos quais o evento adverso ocorreu na etapa de manutenção da sonda e/ou administração de dieta

(conclusão)

\begin{tabular}{|l|l|l|}
\hline \multicolumn{1}{|c|}{$\begin{array}{c}\text { País / } \\
\text { Ano }\end{array}$} & \multicolumn{1}{|c|}{ Evento Adverso / Perfil do paciente } & $\begin{array}{l}\text { Demanda de cuidados adicionais / } \\
\text { evolução clínica do paciente }\end{array}$ \\
\hline $\begin{array}{l}\text { Áustria } \\
2018^{(50)}\end{array}$ & $\begin{array}{l}\text { Obstrução esofágica por formação de bezoar. } \\
\text { Mulher, idosa, admitida por infarto agudo do } \\
\text { miocárdio. }\end{array}$ & $\begin{array}{l}\text { Gastroscopia e agente enzimático } \\
\text { para remoção do bezoar. } \\
\text { Estudo não relata evolução clínica. }\end{array}$ \\
\hline $\begin{array}{l}\text { Sri Lanka. } \\
2018^{(51)}\end{array}$ & $\begin{array}{l}\text { Síndrome da sonda Enteral. Lesão laríngea } \\
\text { provocada pela sonda, causando paresia das } \\
\text { pregas vocais e edema laríngeo. } \\
\text { Mulher, 76 anos, admitida por Acidente Vascular } \\
\text { Cerebral Isquêmico. }\end{array}$ & $\begin{array}{l}\text { Broncoscopia, ventilação mecânica } \\
\text { e traqueostomia. A sonda enteral foi } \\
\text { substituída por gastrostomia. } \\
\text { Alta hospitalar. }\end{array}$ \\
\hline
\end{tabular}

Fonte: Elaboração própria.

Nove artigos descreveram incidentes e EA relacionados à remoção da SE (Quadro 3). A complicação mais frequente foi dificuldade na remoção por presença de nó ou emaranhado da sonda em si própria $(n=5)$. Um estudo apresentou o caso de sutura da SE à anastomose em cirurgia de gastrectomia, impossibilitando a sua retirada. Dois estudos relataram EA misto, relacionado à inserção inadvertida da sonda no trato respiratório, cujo dano ocorreu no momento da remoção da sonda. Em seis estudos, os pacientes apresentaram melhora clínica e/ou alta hospitalar. Um estudo não relatou desfecho clínico e um óbito foi descrito em consequência do pneumotórax hipertensivo secundário à remoção da sonda (inadvertidamente inserida no pulmão). Um trabalho não apresentou demanda de cuidados ou exames adicionais.

Quadro 3 - Caracterização dos estudos nos quais o evento adverso ocorreu na etapa de remoção da sonda enteral (continua)

\begin{tabular}{|l|l|l|}
\hline \multicolumn{1}{|c|}{ País /Ano } & \multicolumn{1}{|c|}{ Evento Adverso / Perfil do paciente } & $\begin{array}{l}\text { Demanda de cuidados adicionais } \\
\text { / evolução clínica do paciente }\end{array}$ \\
\hline $\begin{array}{l}\text { China } 2010^{(10)} \\
\text { Enovelamento da sonda de 3x4 centímetros, } \\
\text { provocando sua obstrução A remoção } \\
\text { provocou lacerações no esôfago. } \\
\text { Homem, 53 anos, admitido por pneumonia. } \\
\text { Doença de Parkinson, câncer de cabeça e } \\
\text { pescoço prévios. }\end{array}$ & $\begin{array}{l}\text { Endoscopia para avaliação das } \\
\text { lesões esofágicas. } \\
\text { Estudo não relata evolução clínica, } \\
\text { mas refere melhora das lesões } \\
\text { esofágicas em cinco semanas. }\end{array}$ \\
\hline $\begin{array}{l}\text { Dinamarca } \\
2016^{(15)}\end{array}$ & $\begin{array}{l}\text { Inserção no lobo inferir do pulmão direito. À } \\
\text { retirada, paciente desenvolveu pneumotórax } \\
\text { hipertensivo. } \\
\text { Mulher, 87 anos, admitida por fibrilação atrial } \\
\text { e Acidente Vascular Isquêmico durante a } \\
\text { internação. }\end{array}$ & $\begin{array}{l}\text { Raio-X de tórax. Não há relato de } \\
\text { cuidados adicionais. } \\
\text { Obito. }\end{array}$ \\
\hline $\begin{array}{l}\text { Reino Unido } \\
2009^{(52)}\end{array}$ & $\begin{array}{l}\text { Ponta distal emaranhada na sutura cirúrgica. } \\
\text { Mulher, 59 anos, admitida para herniorrafia de } \\
\text { hiato por laparoscopia. }\end{array}$ & $\begin{array}{l}\text { Endoscopia para remoção da sonda. } \\
\text { Alta hospitalar. }\end{array}$ \\
\hline $\begin{array}{l}\text { Estados } \\
\text { Unidos da } \\
\text { América } \\
2011^{(53)}\end{array}$ & $\begin{array}{l}\text { Sonda de difícil inserção. À retirada para nova } \\
\text { tentativa de introdução, a sonda apresentou } \\
\text { resistência, ponta distal da sonda apresentava- } \\
\text {-se emaranhada em si própria e paciente } \\
\text { cursou com epistaxe. } \\
\text { Homem, 78 anos, admitido por obstrução } \\
\text { intestinal. }\end{array}$ & $\begin{array}{l}\text { Raio-X de crânio, para identificar } \\
\text { a posição da sonda. Consulta ao } \\
\text { otorrinolaringologista, para fixar } \\
\text { a conduta e fibroscopia, para } \\
\text { remoção da sonda. } \\
\text { Estudo não relata evolução clínica. }\end{array}$ \\
\hline
\end{tabular}


Quadro 3 - Caracterização dos estudos nos quais o evento adverso ocorreu na etapa de remoção da sonda enteral

(conclusão)

\begin{tabular}{|c|c|c|}
\hline País /Ano & Evento Adverso / Perfil do paciente & $\begin{array}{l}\text { Demanda de cuidados adicionais } \\
\text { / evolução clínica do paciente }\end{array}$ \\
\hline $\begin{array}{l}\text { Estados } \\
\text { Unidos da } \\
\text { América } \\
2013^{(54)}\end{array}$ & $\begin{array}{l}\text { Inserção no brônquio direito, ponta distal no } \\
\text { ângulo costofrênico, adjacente à pleura. Na } \\
\text { remoção, ocorreu pneumotórax. } \\
\text { Mulher, } 85 \text { anos, admitida por desidratação. }\end{array}$ & $\begin{array}{l}\text { Raio-X de tórax antes e após } \\
\text { a remoção da sonda. Oxigênio } \\
\text { suplementar. } \\
\text { Estudo relata melhora clínica. }\end{array}$ \\
\hline $\begin{array}{l}\text { Emirados } \\
\text { Árabes } \\
2016^{(55)}\end{array}$ & $\begin{array}{l}\text { Sonda obstruída, apresentava-se emaranhada } \\
\text { em si própria, localizada na nasofaringe. } \\
\text { Tentativa de remoção da sonda sem sucesso. } \\
\text { Homem, } 74 \text { anos, admitido por Acidente } \\
\text { Isquêmico Transitório, incapacidade de } \\
\text { deglutir. }\end{array}$ & $\begin{array}{l}\text { Raio-X de crânio para identificar a } \\
\text { localização da sonda. Fibroscopia } \\
\text { para remoção. } \\
\text { Estudo relata melhora clínica e } \\
\text { transferência para enfermaria. }\end{array}$ \\
\hline $\begin{array}{l}\text { Reino Unido } \\
2017^{(56)}\end{array}$ & $\begin{array}{l}\text { Resistência ao remover a sonda ocasionada por } \\
\text { nó na ponta distal. Paciente não teve danos na } \\
\text { remoção. } \\
\text { Mulher, } 75 \text { anos, admitida por obstrução } \\
\text { intestinal. }\end{array}$ & $\begin{array}{l}\text { Sem demandas adicionais. } \\
\text { Melhora clínica e alta hospitalar. }\end{array}$ \\
\hline $\begin{array}{l}\text { Grécia } \\
2017^{(57)}\end{array}$ & $\begin{array}{l}\text { Formação de looping, impossibilitando a } \\
\text { retirada. } \\
\text { Mulher, } 90 \text { anos, admitida no setor de } \\
\text { endoscopia por impossibilidade de remoção } \\
\text { da sonda. História de hérnia de hiato. }\end{array}$ & $\begin{array}{l}\text { Endoscopia para remoção da sonda. } \\
\text { Não relata evolução clínica. }\end{array}$ \\
\hline $\begin{array}{l}\text { Arábia } \\
\text { Saudita } \\
2018^{(58)}\end{array}$ & $\begin{array}{l}\text { Inserção pré-gastrectomia total. À retirada, a } \\
\text { sonda apresentou resistência. Endoscopia } \\
\text { constatou que a sonda havia sido suturada } \\
\text { junto à anastomose. Homem, } 41 \text { anos, } \\
\text { admitido para gastrectomia por câncer de } \\
\text { estômago. }\end{array}$ & $\begin{array}{l}\text { Endoscopia para remoção da sonda. } \\
\text { Alta hospitalar. }\end{array}$ \\
\hline
\end{tabular}

Fonte: Elaboração própria.

\section{Discussão}

O presente estudo identificou incidentes e eventos adversos relacionados à inserção, manutenção e remoção de SE, descritos por meio de relatos de casos provenientes de diferentes países. Os EA são decorrentes de motivos variados e os danos foram de diversas magnitudes. Enquanto alguns pacientes apresentaram evolução favorável, apesar de demandarem tratamentos adicionais, um número considerável evoluiu para óbito. Quase um terço dos estudos não apresentou dados do desfecho clínico do paciente.

É importante destacar que a Nutrição Enteral é descrita como adjuvante na recuperação de pacientes, reduzindo o tempo de internação, complicações sépticas e mortalidade, além dos custos aos sistemas de saúde ${ }^{(1-2)}$. No entanto, inserir e manter dispositivos de alimentação como as SE de inserção nasal, são procedimentos que guardam riscos de incidentes ou $\mathrm{EA}^{(1-2)}$, como revelaram os resultados do presente estudo. As SE são inseridas maioritariamente por enfermeiros, à beira do leito e sem visualização do trajeto, o que impossibilita garantir que a sonda percorra o trato gastrointestinal em todas as inserções ${ }^{(1-4)}$.

Os dados sobre mau posicionamento de SE variam de 0,3 a $15 \%{ }^{(40)}$. Entre os relatos mais frequentes no presente estudo, estão a inserção da SE em árvore brônquica e pulmão ${ }^{(34-38)}$ e no cérebro $^{(12,14,24,29)}$, enquanto a perfuração esofágica ${ }^{(26)}$, gástrica $^{(11)}$, intestinal ${ }^{(25)}$ e inserção da sonda em átrio ${ }^{(27)}$ foram menos reportados. Em alguns casos, condições prévias do paciente contribuíram para essas intercorrências ${ }^{(11-13,25,27,29,34,52)}$, reforçando a 
necessidade de cuidados e avaliação da história clínica, além do conhecimento, pela equipe de enfermagem, das indicações e contraindicações de inserção de sondas ${ }^{(1-4)}$. Exemplos disso são a recomendação ${ }^{(1)}$ estrita que contraindica a inserção de sonda por via nasal em pacientes com trauma de crânio, e o estudo ${ }^{(59)}$ que demonstrou maior risco de sangramento em pacientes trombocitopênicos submetidos à inserção de sonda.

Tais achados são uma forma de alerta às equipes assistenciais, estudantes e cuidadores quanto aos riscos de complicações desse procedimento. Nesse sentido, outras técnicas de inserção vêm sendo estudadas, como o posicionamento da sonda através de laringoscopia guiada por vídeo ${ }^{(60)}$ ou dispositivos eletromagnéticos ${ }^{(61)}$. Em estudo que avaliou a inserção da SE através desse último ${ }^{(61)}$, identificou-se sensibilidade de 98\% (IC95\%: 93,9\% - 99,7\%) e especificidade de 100\% (IC95\%: 48\% - 100\%) quando comparado ao Raio-X convencional. Essa técnica possibilita a identificação imediata da localização da sonda, evitando que permaneça em sítios inadequados até a realização do exame de imagem. Contudo, essas tecnologias ainda esbarram na capacitação e, mais especialmente, nos custos de implementação.

A administração de dieta no sítio respiratório é um dos EA frequentes na assistência aos pacientes usuários de SE. Apesar de existir preocupação em determinar seu posicionamento adequado no momento da inserção, bem como recomendações nacionais ${ }^{(3-4)}$ e internacionais ${ }^{(1-2)}$ para realização de exame de imagem, os resultados do presente estudo demonstraram que diferentes centros ainda adotavam apenas testes clínicos - ausculta e avaliação do pH - para predizer a localização da sonda ${ }^{(40-45)}$. Nas rotinas assistenciais de inserção e manutenção de SE, os testes à beira do leito já se apresentavam pouco acurados para esse fim ${ }^{(62-63)}$ e tecnologias, como o ultrassom, vêm se mostrando promissoras, mas ainda sem conseguir descartar o Raio- $\mathrm{X}^{(64-65)}$.

Recomendação como da American Society of Parenteral and Enteral Nutrition ${ }^{(1)}$ e regulamentação brasileira (RDC n. 63/2000) ${ }^{(3)}$ estabelecem responsabilidades e Boas Práticas para todas as etapas do processo entre a inserção e a manutenção de SE, mas ainda há desafios na realização segura dessas etapas. A resistência e o desconhecimento são entraves nesse cenário. Em estudo ${ }^{(65)}$ realizado com a equipe de enfermagem, demonstrou-se haver falta de conhecimento teórico sobre os cuidados aos usuários de SE. Além disso, durante suas práticas, poucos profissionais realizavam algum teste para confirmar o posicionamento adequado da ponta distal da sonda.

Menor número de estudos relacionados aos incidentes e EA na etapa da remoção da SE foram encontrados, mas, nem por isso, são menos relevantes. De fato, percebe-se que tanto no âmbito internacional ${ }^{(1-2)}$ como nacional $^{(3-4)}$ há lacuna nas regulamentações e diretrizes no que se refere à remoção da sonda de forma adequada. Tais documentos, norteadores das práticas assistenciais, elaborados por especialistas e que deveriam contemplar todas as etapas (inserção, manutenção e remoção), não abordam aspectos desta última.

Assim, parece importante que o enfermeiro avalie de forma minuciosa ${ }^{(4)}$, não só os fatores de risco para o mau posicionamento, mas também tenha atenção no momento da remoção da SE. A avaliação de exames de imagem recentes em relação ao momento da retirada da sonda, a atenção às situações nas quais há resistência na sua retirada ou vigilância às queixas dos pacientes, podem configurar-se como alternativas na prevenção de incidentes ou EA nessa etapa.

Por fim, cumpre destacar que, no presente estudo, foram descritas as necessidades de exames e procedimentos adicionais que se relacionaram com incidente ou EA na inserção, manutenção e remoção da SE. Conhecer o impacto das intercorrências tanto para os pacientes quanto para os profissionais e instituições ${ }^{(6)}$ pode colaborar para que a criação de protocolos torne a assistência mais segura. Outro dado importante é a ausência de descrição dos desfechos clínicos dos pacientes em 13 estudos $^{(9,11-12,14,27-28,31,33,36,38,47,49-50)}$, o que não permite conhecer o desdobramento do caso e mensurar a magnitude do EA.

O presente estudo contribui para alertar os profissionais da enfermagem para a ocorrência de incidentes e eventos adversos decorrentes da 
assistência aos pacientes em uso de sonda enteral. Somente conhecendo as potenciais complicações durante todo o processo da assistência será possível estabelecer medidas para minimizá-las e evitar a EA não somente ao ambiente hospitalar, mas em qualquer nível da rede de atenção à saúde.

Uma possível limitação deste estudo reside em ter incluído apenas artigos disponíveis na íntegra nas bases de dados pesquisadas, bem como relatos de caso com baixo nível de evidência e nenhum estudo de maior aprofundamento epidemiológico. Isso implica em postular que um número maior de publicações, eventualmente com diferentes tipos de delineamento, possa estar disponível na literatura, relatando outros incidentes e EA.

\section{Conclusão}

Conclui-se que diferentes incidentes e eventos adversos descritos na literatura podem ocorrer na inserção, manutenção e administração de dieta e remoção da sonda enteral. Conhecê-los pode garantir que a assistência de enfermagem seja segura, qualificada e baseada nas melhores evidências científicas.

As avaliações de condições e história clínica do paciente no momento da inserção das sondas parece ser uma importante estratégia para minimizar os riscos de complicações, bem como a atenção para confirmar o posicionamento evidenciado pelo raio-X, ou cuidados minuciosos no procedimento de retirada. Novas pesquisas com delineamento mais robusto podem ser conduzidas com vistas a sintetizar as informações nessa área.

\section{Colaborações:}

1 - concepção, projeto, análise e interpretação dos dados: Franciele Anziliero, Bárbara Elis Dal Soler, Bárbara Amaral da Silva, Ana Paula Almeida Corrêa e Mariur Gomes Beghetto;

2 - redação do artigo e revisão crítica relevante do conteúdo intelectual: Franciele Anziliero, Bárbara Elis Dal Soler, Bárbara Amaral da Silva, Ana Paula Almeida Corrêa e Mariur Gomes Beghetto;

3 - aprovação final da versão a ser publicada: Franciele Anziliero, Bárbara Elis Dal Soler, Bárbara Amaral da Silva, Ana Paula Almeida Corrêa e Mariur Gomes Beghetto.

\section{Referências}

1. Boullata JI, Carrera AL, Harvey L, Escuro AA, Hudson L, Mays A, et al. ASPEN Safe Practices for Enteral Nutrition Therapy. JPEN J Parenter Enteral Nutr. 2017 Jan;41(1):15-103. DOI: $10.1177 / 0148607116673053$

2. McClave SA, Taylor BE, Martindale RG, Warren MM, Johnson DR, Braunschweig C, et al. Guidelines for the Provision and Assessment of Nutrition Support Therapy in the Adult Critically Ill Patient: Society of Critical Care Medicine (SCCM) and American Society for Parenteral and Enteral Nutrition (A.S.P.E.N.). JPEN J Parenter Enteral Nutr. 2016 Feb;40(2):159211. DOI: $10.1177 / 0148607115621863$

3. Brasil. Ministério da Saúde. Agência Nacional de Vigilância Sanitária. Resolução RDC no 63, de 6 de julho de 2000. Fixa os requisitos mínimos exigidos para a Terapia de Nutrição Enteral [Internet]. Brasília (DF); 2000 [cited 2019 Jul 18]. Available from: http://bvsms.saude.gov.br/bvs/ saudelegis/ anvisa/2000/rdc0063_06_07_2000.html

4. Conselho Federal de Enfermagem. Resolução COFEN n 453, de 16 de janeiro de 2014. Aprova a Norma Técnica que dispõe sobre a Atuação da Equipe de Enfermagem em Terapia Nutricional [Internet]. Brasília (DF); 2014 [cited 2019 Jul 18] Available from: http://www.cofen.gov.br/ resolucao-cofen-no-04532014_23430.html

5. Brasil. Ministério da Saúde. Fundação Oswaldo Cruz. Agência Nacional de Vigilância Sanitária. Documento de referência para o Programa Nacional de Segurança do Paciente [Internet]. Brasília (DF); 2014 [cited 2019 Aug 18]. Available from: http:// bvsms.saude.gov.br/bvs/publicacoes/documento_ referencia_programa_nacional_seguranca.pdf

6. Sparks DA, Chase DM, Coughlin LM, Perry E. Pulmonary complications of 9931 narrow-bore nasoenteric tubes during blind placement: a critical review. JPEN J Parenter Enteral Nutr. 2011 Sep;35(5):625-9. DOI: 10.1177/0148607111413898

7. Anziliero F, Beghetto MG. Incidents and adverse events in enteral feeding tube users: warnings 
based on a cohort study. Nutr Hosp. 2018 Feb 27;35(2):259-64. DOI: 10.20960/nh.1440

8. Sano N, Yamamoto M, Nagai K, Yamata K, Ohkohchi N. Nasogastric tube syndrome induced by an indwelling long intestinal tube. World J Gastroenterol. 2016 Apr;22(15):4057-61. DOI: 10.3748/wjg.v22.i15.4057

9. Vielva del CB, Moráis PD, Saldaña GD. Nasogastric tube syndrome: a case report. Acta Otorrinolaringol. 2010;61:85-6. DOI: 10.1016/j.otorri.2009.03.006

10. Tai CM, Wang HP, Lee CT, Chang CY, Wang WL, Tseng $\mathrm{CH}$, et al. Esophageal obstruction by a tangled nasogastric tube. Gastrointest Endosc. 2010 Nov;72(5):1057-8. DOI: 10.1016/j.gie.2010.03.1131

11. Daliya P, White T, Makhdoomi K. Gastric perforation in an adult male following nasogastric intubation. Annals Royal College Surgeons England. 2012;94(7):210-2. DOI: $0.1308 / 003588412 X 131712215023$

12. Psarras K, Lalountas MA, Symeonidis NG, Baltatzis M, Pavlidis ET, Ballas K, et al. Inadvertent insertion of a nasogastric tube into the brain: case report and review of the literature. Clin Imaging. 2012 Sep-Oct;36(5):587-90. DOI: 10.1016/j.clinimag.2011. 12.020

13. Chandra R, Kumar P. Intracranial introduction of a nasogastric tube in a patient with severe craniofacial trauma. Neurol India 2010 Sep;58(5):804-5. DOI: 10.4103/0028-3886.72192

14. Araimo F, Caramia R, Meschesi E. Intracranial placement of a nasogastric tube in a non-trauma patient. HSR Proc Intensive Care Cardiovasc Anesth [Internet]. 2011 [cited 2019 Jul 19];3(1):71. Available from: https://www.ncbi.nlm.nih.gov/ pmc/articles/PMC3484606/pdf/hsrp-03-071.pdf

15. Andresen EN, Frydland M, Usinger L. Deadly pressure pneumothorax after withdrawal of misplaced feeding tube: a case report. J Med Case Rep. 2016 Feb;10:30. DOI: 10.1186/ s13256-016-0813-y

16. Thorat JD, Wang E. Gastric acid burns because of a disconnected nasogastric tube. CMAJ. 2008 Mar;178(6):680. DOI: 10.1503/cmaj.070864

17. Cervo AS, Magnago TSBS, Carollo JB, Chagas BP, Oliveira AS, Urbanetto JS. Eventos adversos relacionados ao uso da terapia nutricional enteral. Rev Gaúcha Enferm. 2014 jun;35(2):53-9. DOI: 10.1590/1983-1447.2014.02.42396
18. Souza MT, Silva MD, Carvalho R. Revisão integrativa: o que é e como fazer. Einstein. 2010 jan/mar;8(1):102-6. DOI: 10.1590/s167945082010 rw 1134

19. Moher D, Shamseer L, Clarke M, Ghersi D, Liberati A, Petticrew M. PRISMA-P Group. Preferred reporting items for systematic review and meta-analysis protocols (PRISMA-P) 2015 statement. Syst Rev. 2015 Jan;4(1). DOI: 10.1186/2046-4053-4-1

20. Santos CMC, Pimenta CAM, Nobre MRC. The PICO strategy for the research question construction and evidence search. Rev Latino-Am Enfermagem. 2007 jun;15(3):508-11. DOI: 10.1590/ S0104-11692007000300023

21. Brasil. Presidência da República. Casa Civil. Lei $\mathrm{n}^{\circ} 12.853$, de 14 de agosto de 2013. Altera os arts. 5- , 68, 97, 98, 99 e 100, acrescenta arts. 98-A, 98-B, 98-C, 99-A, 99-B, 100-A, 100-B e 109-A e revoga o art. 94 da Lei no 9.610 , de 19 de fevereiro de 1998, para dispor sobre a gestão coletiva de direitos autorais, e dá outras providências [Internet]. Brasília (DF); 2013 [cited 2019 Aug 30]. Available from: http://www.planalto.gov.br/ ccivil_03/_Ato2011-2014/2013/Lei/L12853.htm

22. Brasil. Presidência da República. Casa Civil. Lei $n^{\circ}$ 9.610, de 19 de fevereiro de 1998. Altera, atualiza e consolida a legislação sobre direitos autorais e dá outras providências [Internet]. Brasília (DF); 1998 [cited 2019 Nov 3]. Available from: http://www.planalto.gov.br/ccivil_03/leis/ 19610.htm

23. Hegde HV, Raghavendra Rao P. A near miss; malpositioned nasogastric tube in the left bronchus of a spontaneously breathing critically-ill patient. Current Anaesth Crit Care. 2010;21(2):94-6. DOI: 10.1016/j.cacc.2009.12.002

24. Roka YB, Shrestha M, Puri PR, Aryal S. Fatal inadvertent intracranial insertion of a nasogastric tube. Neurol India 2010 Sep-Oct;58(5):802-4. DOI: 10.4103/0028-3886.72191

25. Liang TJ, Liu SI, Chou NH. Small Bowel Perforation by Nasogastric Tube. Clin Gastroenterol Hepatol. 2011 Jul;9(7):A34. DOI: 10.1016/j.cgh.2011.02.024

26. Gómez-Ríos MA, Pérez Gil J, Ramos López L, López Sánchez M, López Álvarez S, Pensado Castiñeiras A. Complicaciones tras esofagoscopia rígida y posterior colocación de sonda Nasogástrica. Rev Esp Anestesiol Reanim. 2011;58(1):67. DOI: 10.1016/s0034-9356(11)70705-8 
27. Lyske J. A rare complication of nasogastric tube insertion. BMJ Case Rep. 2011 Sep 28;2011:1-2. DOI: $10.1136 /$ bcr.08.2011.4606

28. Viteri G, Larrache J, Díaz ML, Alcalde JM, Lopez-Olaondo L, Bilbao JI. Nasogastric tube found in the right atrium. J Vasc Interv Radiol. 2012 May;23(5):721-2. DOI: 10.1016/j.jvir.2012.01.067

29. Hanna AS, Grindle CR, Patel AA, Rosen MR, Evans JJ. Inadvertent insertion of nasogastric tube into the brain stem and spinal cord after endoscopic skull base surgery. Am J Otolaryngol. 2012 Jan-Feb;33(1):178-80. DOI: 10.1016/j.amjoto.2011.04.001

30. Nanjegowda N, Umakanth S, Undrakonda V. Laryngospasm during extubation. Can nasogastric tube be the culprit? BMJ Case Rep. 2013 Jun 18;2013:bcr2013009645. DOI: 10.1136/ bcr-2013-009645

31. KerforneT, Chaillan M, Geraud L, Mimoz O. Ultrasound diagnosis of nasogastric tube misplacement into the trachea during bypass surgery. Br J Anaesth. 2013 Dec;111(6):1032-3. DOI: $10.1093 / \mathrm{bja} /$ aet399

32. Paul V, Kupfer Y, Tessler S. Severe Epistaxis after Nasogastric Tube Insertion Requiring Arterial Embolisation. BMJ Case Rep. 2013 Jan 18;2013:pii:bcr2012007278. DOI: 10.1136/ bcr-2012-007278

33. Bastida Chacón A, Navarro-García N, Correa Chacón OC, Betancourt Bastidas JR. Iatrogenic pneumothorax secondary to the insertion of a nasogastric tube. Rev Esp Anestesiol Reanim. 2015 Mar;62(3):178. DOI: 10.1016/j.redar.2014.03.015

34. Kalava A, Clark K, McIntyre J, Yarmush JM, Lizardo T. Mistaken Endobronchial Placement of a Nasogastric Tube During Mandibular Fracture Surgery. Anesth Prog. 2015 Fall;62(3):114-7. DOI: 10.2344/13-00021R1.1

35. Fonseca RV, Domingos G, Alves P, Ribeiro R. Placement of nasogastric tube complicated by hydropneumothorax. Intensive Care Med. 2015 Nov;41(11):1969-70.DOI: 10.1007/S00134-015-3824-Z

36. Lübbe-Vázquez CF, Cabrera-Arrocha J, Hernández Socorro CR. Nasogastric feeding tube with distal tip in right pleural cavity. Med Intensiva. 2015 Apr;39(3):198. DOI: 10.1016/j.medin.2014.10.002

37. Al Saif N, Hammodi A, Al-Azem MA, Al-Hubail R. Tension Pneumothorax and Subcutaneous Emphysema Complicating Insertion of Nasogastric
Tube. Case Rep Crit Care. 2015;2015:690742. DOI: $10.1155 / 2015 / 690742$

38. SENSAR. Sonda nasogástrica de nutrición enteral en localización pulmonar. Caso SENSAR del trimestre. Rev Esp Anestesiol Reanim. 2017 Jan;64(1):e1-e5. DOI: 10.1016/j.redar.2016.06.003

39. Abidali A, Mangram A, Shirah GR, Wilson W, Abidali A, Moeser P, et al. Bilateral Pneumothoraces in a Trauma Patient After Dobhoff Tube Insertion. Am J Case Rep. 2018 Mar 5;19:244-8. DOI: 10.12659/ ajcr.906846

40. Lim JY, Yong E, Aneez DBA, Tham CH. A simple procedure gone wrong: pneumothorax after inadvertent transbronchial nasogastric tube insertion necessitating operative management. J Surg Case Rep. 2019 Jun 14;2019(6):rjz186. DOI: $10.1093 /$ jscr/rjz186

41. Ishigami A, Kubo S, Tokunaga I, Gotohda T, Nishimura A. An autopsy case of severe pleuritis induced by misinsertion of a nasogastric nourishment tube: Diagnostic significance of multinucleated giant cells. Legal Med (Tokyo). 2009 Jul;11(4):191-4. DOI: 10.1016/j. legalmed.2009.02.065

42. $\mathrm{Xu} \mathrm{Z}, \mathrm{Li}$ W. Aspiration pneumonia caused by inadvertent insertion of gastric tube in an obtunded patient postoperatively. BMJ Case Rep. 2011 Nov 8;2011:bcr062011441. DOI: 10.1136/ bcr.06.2011.4411

43. Kao X, Yu W, Zhu W, Li N, Li J. Repeated lung lavage with extracorporeal membrane oxygenation treating severe acute respiratory distress syndrome due to nasogastric tube malposition for enteral nutrition: a case report. Asia Pac J Clin Nutr [Internet]. 2012 [cited 2019 Sep 21];21(4):638-41. Available from: https://www.ncbi.nlm.nih.gov/ pubmed/23017323

44. Sellers CK. False-Positive $\mathrm{pH}$ aspirates after nasogastric tube insertion in head and neck tumour. BMJ Case Rep. 2012 Aug 27;2012:pii: bcr2012006591. doi: 10.1136/bcr-2012-006591

45. Tawfic QA, Bhakta P, Date RR, Sharma PK. Esophageal bezoar formation due to solidification of enteral feed administered through a malpositioned nasogastric tube: Case report and review of the literature. Acta Anaesthesiol Taiwan. 2012 Dec;50(4):188-90. DOI: 10.1016/j.aat.2012.12.002

46. González López R, Torres García MI, Seoane Vigo M, Arija Val JF. Right hydropneumothorax due to enteral feding. 
Nasogastric tube inside airway. Rev Esp Geriatr Gerontol. 2012 Mar-Apr;47(2):87-8. DOI: 10.1016/j. regg.2011.09.006

47. Leonard, S, O'Connell S, O'Connor M. Complications of nasogastric tube placementdon't blow it. Ir Med J [Internet]. 2012 Apr [cited 2019 Sep 23];105(4):116-7. Available from: https://www.ncbi.nlm.nih.gov/pubmed/?ter $\mathrm{m}=$ Complications + of + nasogastric + tube + place ment--don\%27t+blow+it

48. Cereda E, Costa U, Caccialanza R, Pedrolli C. A malfunctioning nasogastric feeding tube. Nutr Hosp. 2013;28(1):229-31. DOI: 10.3305/ nh.2013.28.1.6259

49. Gil-Almagro F, Carmona-Monge FJ. Oesophageal bezoar as a complication of enteral nutrition in critically ill patients. Two case studies. Intensive Crit Care Nurs. 2016 Feb;32:29-32. DOI: 10.1016/j. iccn.2015.08.003

50. Rainer F, Prenner G, Binder LP, Fickert P, Plank J. Case of nasogastric tube dysfunction. Gut Month J. 2018;68(2):206-62. DOI: 10.1136/ gutjnl-2017-315619

51. Perera HMM. NG tube syndrome: a case report of a rare complication of NG tube. Ceylon Med J. 2018 Dec;63(4):192-3. DOI: 10.4038/cmj. v63i3.8773

52. Shaaban H, Armstrong C. Nasogastric tube accidentally stitched to the stomach during laparoscopic antireflux surgery. Endoscopy. 2009; 41(Suppl2):E61. DOI: 10.1055/s-0028-1103464

53. Egan DJ, Shami N. Self-knotting of a nasogastric tube. West J Emerg Med [Internet]. 2011 May [cited 2019 Sep 27];12(2):266-7. Available from: https:// www.ncbi.nlm.nih.gov/pubmed/21691541

54. PaulV, Shenoy A, KupferY, TesslerS. Pneumothorax occurring after nasogastric tube removal. BMJ Case Rep. 2013 Dec 2;2013:pii:bcr2013010419. DOI: $10.1136 /$ bcr-2013-010419

55. Hirwa KD, Toshniwal N. Knotted nasogastric tube in the posterior nasopharynx: A case report. Qatar Med J. 2016 Dec;2016(2):11. DOI: 10.5339/ qmj.2016.11

56. Chavda V, Alhammali T, Farrant J, Naidu L, El-Rabaa S. Nasogastric tube knotting: a rare and potentially overlooked complication among healthcare professionals. BMJ Case Rep. 2017 Sep 7;2017:pii:bcr-2017-220287. DOI: 10.1136/ bcr-2017-220287
57. Galanopoulos M, Tsigaridas A, Varytimiadis L, Papaefthymiou A, Kalampalikis L, Ladias S, et al. A forgotten nasogastric feeding tube that refuses to get out. Clin Case Rep. 2017 Jan 17;5(2):205-7. DOI: $10.1002 / \mathrm{ccr} 3.818$

58. Azzam AZ, Azzam KA, Amin T. Removal of Nasogastric Tube Accidentally Stitched to Rouxen-Y Oesophagojejunostomy Following a Radical Gastrectomy for Stomach Cancer: Case report and review of the literature. Sultan Qaboos Univ Med J. 2018 Feb;18(1):e110-e111. DOI: 10.18295/ squmj.2018.18.01.020

59. Patel RP, Canada TW, Nates JL. Bleeding Associated with Feeding Tube Placement in Critically Ill Oncology Patients With Thrombocytopenia. Nutr Clin Pract. 2015 Feb;31(1):111-5. DOI: $1010.1177 / 0884533615598964$

60. Lee XL, Yeh LC, Jin YD, Chen CC, Lee MH, Huang PW. Nasogastric tube placement with video-guided laryngoscope: A manikin simulator study. J Chin Med Assoc. 2017 Aug;80(8):492-7. DOI: $10.1016 /$ j.jcma.2017.01.009

61. Bear DE, Champion A, Lei K, Smith J, Beale R, Camporota L, et al. Use of an Electromagnetic Device Compared With Chest X-ray to Confirm Nasogastric Feeding Tube Position in Critical Care. J Parenter Enteral Nutr. 2016 May;40(4):581-6. DOI: $10.1177 / 0148607115575034$

62. Beghetto MG, Anziliero F, Leães DM, De Mello ED. Sondagem enteral: concordância entre teste de ausculta e raio-x na determinação do posicionamento da sonda. Rev Gaúcha Enferm. 2015 Oct/Dec;36(4):98-103. DOI: 10.1590/1983-1447.2015.04.54700

63. Baskin WN. Acute Complications Associated with Bedside Placement of Feeding Tubes. Nutr Clin Pract. 2006 Feb;21(1):40-55. DOI: $10.1177 / 011542650602100140$

64. Lin T, Gifford W, Lan Y, Qin X, Liu X, Wang J, et al. Diagnostic accuracy of ultrasonography for detecting nasogastric tube (NGT) placement in adults: A systematic review and meta analysis. Int J Nurs Stud. 2017 Jun;71:80-8. DOI: 10.1016/j. ijnurstu.2017.03.005

65. Hermann AP, Cruz EDA. Enfermagem em nutrição enteral: investigação do conhecimento e da prática assistencial em hospital de ensino. Cogitare Enferm. 2008 out-dez;13(4):520-5. DOI: 10.5380/ ce.v13i4.13111 
66. De Aguilar-Nascimento JE, Kudsk KA. Clinical costs of feeding tube placement. JPEN J Parenter Enteral Nutr. 2007 Jul-Aug;31(4):269-73. DOI: $10.1177 / 0148607107031004269$
Recebido: 13 de outubro de 2019

Aprovado: 12 de novembro de 2019

Publicado: 2 de março de 2020

A Revista Baiana de Enfermagem utiliza a Licença Creative Commons - Atribuição-NãoComercial 4.0 Internacional. https://creativecommons.org/licenses/by-nc/4.0/ Este artigo é de acesso aberto distribuído sob os termos da Licença Creative Commons (CC BY-NC). Esta licença permite que outros remixem, adaptem e criem a partir do seu trabalho para fins não comerciais. Embora os novos trabalhos tenham de lhe atribuir o devido crédito e não possam ser usados para fins comerciais, os usuários não têm de licenciar esses trabalhos derivados sob os mesmos termos. 